\title{
Relationship between Pre-Eclampsia, Renal Impairment and Hepatic Insufficiency among Pregnant Women in Al-Jouf Area
}

\author{
Omnia Magdy Hendawy ${ }^{1,2, *}$, Shaimaa Hussein ${ }^{1}$ and Eman A. Harahsheh ${ }^{3}$ \\ ${ }^{1}$ Department of Pharmacology, Faculty of Pharmacy, Jouf University, Saudi Arabia \\ ${ }^{2}$ Department of Clinical Pharmacology, Faculty of Medicine, Beni-Suef University, Egypt \\ ${ }^{3}$ Department of Clinical Pharmacy and Pharmacy Practice, Faculty of Pharmaceutical Sciences, Hashemite \\ University, P.O. 330127, Zarqa 13133, Jordon
}

\begin{abstract}
Background: Pre-eclampsia is a pregnancy-specific syndrome. It affects $3-5 \%$ of pregnant women and is characterized by oedema, high blood pressure, and proteinuria. Moreover, in women with pre-eclampsia dysfunction of many organs, such as kidney and liver, is diagnosed, while in the case of foetus growth restriction is observed. Preeclampsia, when left untreated, can lead to a high mortality rate. In low-income countries, this disorder is one of the main causes of maternal and child mortality. Pre-eclampsia predisposes women in later life to cardiovascular diseases. So far, in acute cases of pre-eclampsia stabilization of the mother and fotus, and finally, termination of pregnancy at a time optimal for both sides can only be considered.
\end{abstract}

Methods: The present work is designed to investigate the relationship between pre-eclampsia, renal and hepatic insufficiency in the Al-Jouf area through collecting information from the electronic database of maternity hospital for 100 pregnant women who suffered from pre-eclampsia compared with normal pregnancies.

Results: The prevalence of pre-eclampsia is more prone in eldest women (older than 35 years old) almost $45 \%$ than younger women (20-25 years old), PC to MPV ratio value showed a significant suppression in pre-eclamptic pregnancies in comparison with normal pregnant women while $\mathrm{HbA} 1 \mathrm{c} \%$ value indicated a significant increase in the pre-eclamptic cases than the healthy pregnant women. Renal indices, serum creatinine, urea, and albumin were significantly higher in the pre-eclamptic women than in women with normal pregnancies.

Conclusion: There is a tight relationship between hypertensive disorders during pregnancies, chronic renal disorders and hepatic insufficiency.

Keywords: Pre-eclampsia, Renal impairment and Hepatic disease.

\section{INTRODUCTION}

Pre-eclampsia is a serious pathological disorder characterized by elevated blood pressure after 20 weeks of pregnancy that may cause more than 60,000 deaths of pregnant women all over the world every year. It is characterized by protein in the urine, major organ impairment of the mother, either the kidney, the liver, central nervous system, the blood, or abnormal foetal growth in almost $5 \%$ of pregnancies. These complications might lead to a high fatality rate for both mother and foetus [1].

It is difficult to diagnose a case of pre-eclampsia. The maternal phenotype of pre-eclampsia is usually accompanied by endothelial cell inflammation. The more extreme beginning stage placental phenotype is related to foetal development limitation. Pregnant women may give late-beginning hypertension and proteinuria, with no presence of foetal development

*Address correspondence to this author at the Department of Pharmacology, Faculty of Pharmacy, Jouf University, Saudi Arabia; Tel: 00966593419560; E-mail: omhendawy@ju.edu.sa limitation close to term. In acknowledgment of the multifaceted phenotype of pre-eclampsia, the American College of Obstetrics and Gynaecology refreshed its meaning of this condition in 2016 as follows: [2] Maternal circulatory pressure $>140 / 90 \mathrm{~mm} \mathrm{Hg}$ on multiple times at any rate 4 hours separated following 20 weeks of origination in a lady with recently estimated ordinary pulse. Maternal blood pressure > 160/110 mm Hg: hypertension can be confirmed with a short interval (minutes) to facilitate timely antihypertensive therapy and one of the following:

- Proteinuria: $>300 \mathrm{mg}$ in a 24 hours urine collection.

- $\quad$ Dipstick reading of $1+$.

- Decreased platelets count.

- Kidney impairment.

- Hepatic insufficiency.

- Central nervous system or optical symptoms.

Most of the pregnant women are asymptomatic even with severe illness. Douglas and Redman

(C) 2020 SET Publisher 
reported that $38 \%$ of pregnant ladies didn't report an elevation of systemic blood pressure or the presence of protein in the urine [3]. Unrecognized foetal trade-off adds to the pace of foetal downfall, and 1 of every 20 stillbirths without inborn anomaly is muddled by or owing to pre-eclampsia [4]. Distortions in the development of the placental vasculature early in pregnancy may lead may lead to under-perfusion of organs causing ischemia/hypoxia, which then leads to the release of anti-vascular agents in the illiterate blood circulation that change the maternal systemic lining function and cause high blood pressure and manifestations for other disease (blood, nervous, heart, lung, kidney, and liver diseases) [5].

This change in the normal vascular balance towards the anti-vascular state can lead to high blood pressure, proteinuria, glomerular vascular endothelium, HELLP (haemolysis, elevated liver enzymes and low platelets) and cerebral oedema - clinical signs of pre-eclampsia. Recent discoveries of systematically organized antiangiogenic agents provide promises for future tests to predict and diagnose pre-eclampsia as well as a treatment approach [6]. Oxidative stress may also play an important role in the pathogenesis of pre-eclampsia. The main source of reactive oxygen species (ROS) is xanthine oxidase $(\mathrm{XO})$ and this enzyme occurs mainly in the liver. One hypothesis is that the increased purine degradation of chorionic hypoxia leads to an increased ROS production in the mother's liver and its release into the illiterate circulation that causes endothelial cell damage [7]. Abnormalities in the mother's immune system and decreased intestinal immune tolerance appear to play key roles in pre-eclampsia. One of the main differences in pre-eclampsia is the shift towards IFN- production. The origin of IFN has not been clearly defined and they can be natural killer cells of the uterus, chorionic dendritic cells that modulate helper $\mathrm{T}$ cell responses, cause changes in the synthesis or response of regulatory molecules, or changes in the regulatory function of $\mathrm{T}$ cells in pregnancy.

Anomalous immune responses that enhance preeclampsia may also be caused by a change in fetal recognition or due to an inflammatory stimuli. It has been documented that fetal cells, such as fetal red aromas, as well as the DNA of a cell-free fetus increase in the mother's blood circulation in women with pre-eclampsia. This results in the hypothesis that pre-eclampsia is a pathological process permitted by the placenta lesion such as hypoxia by increasing the fetal substances in the maternal blood circulation, which in turn leads to an immune response and endothelial damage, and ultimately results in preeclampsia [8].

The National Institute for Health and Care Excellence (NICE) suggests a rundown of maternal hazard factors that can be utilized to recognize ladies who are at high hazard for pre-eclampsia in whom ibuprofen ought to be begun from 12 weeks' incubation [9]. Solid hazard factors incorporate past pre-eclampsia or hypertension in pregnancy, incessant kidney malady, interminable hypertension, diabetes (type 1 or 2) [10] immune system issues, for example, foundational lupus erythematosus or antiphospholipid condition and sub-clinical hypothyroidism or thyroid antibodies $[11,12]$. To differentiate between preeclampsia and other causes of high blood pressure, proteinuria is the most specific diagnostic sign of preeclampsia due to temporary damage of the kidney filter leading to the spilling of protein in urine especially albumin [13]. Early control of maternal blood pressure is an important method to prevent further complications of pre-eclampsia such as cerebral stroke, convulsions (eclampsia), pulmonary oedema, bleeding due to liver damage and loss of vision. When pre-eclampsia or eclampsia damages the liver and blood cells, you can get a complication called HELLP syndrome. That stands for: haemolysis, elevated liver enzymes and low platelets count. Preeclampsia can also cause placental abruption from the uterus that can lead to stillbirth [14].

Treatment of pre-eclampsia depends on the sevenday extension of growth, if the pregnancy is at 37 weeks or later, the main successful strategy for treatment is to remove the child to treat pre-eclampsia and stay away from further complications.

If the gestation period is less than 37 weeks, however, the woman and the gynecologist may consider treatment options that give the fetus a greater chance of development, for example, corticosteroids, depending on the severity of the condition. The HR service provider may consider alternatives associated with it:

- If the level of hypertension is mellow and the maternal side effects are controlled, approach the mother to go for bed rest to diminish circulatory strain and increment blood stream to the placenta.

- Anticonvulsive treatment, for example, magnesium sulfate.

- If the level of hypertension is extreme, the mother ought to be admitted to the emergency 
clinic under close observation and start the treatment by intravenous antihypertensive and anticonvulsants. Preterm conveyance might be fundamental, regardless of whether that implies likely entanglements for the baby, given the danger of serious maternal inconveniences [1517].

The present study is designed to highlight the prevalence of pre-eclampsia in Al-Jouf area, Saudi Arabia regarding the age of patients, week of occurrence of hypertension during gestation period, presence of kidney impairment, and liver complications compared to normal pregnant women

\subsection{Background and Significance}

Previous studies that were conducted on preeclampsia mostly focused on the implication of health system strength [18].

Other studies focused on impact of severe preeclampsia on maternal and fetal outcomes in preterm deliveries [19]. Another study focused on strategy for standardization of pre-eclampsia research study design [20].

\subsection{Gap of Literature and Description}

This study is the first descriptive study to evaluate the percentage of preeclampsia in pregnant women in the Al-Jouf region by gathering information from the electronic database of the Maternity and Children's Hospital, Sakaka, Al-Jouf region, Kingdom of Saudi Arabia (KSA)

\section{RESEARCH DESIGN AND METHOD}

Study area: At Maternity and Children's Hospital in Sakaka, Aljouf region, Saudi Arabia.

Sampling technique: Taking patients history sheet from the electronic database of the hospital. Sample size: 200 patients.

Time: The study was conducted from FebruaryMay 2018 after getting ethical approval.

Sample criteria: A cross-sectional study was conducted at Maternity and Children's Hospital, Sakaka, Al-Jouf region, Kingdom of Saudi Arabia (KSA) during February-May 2018. Pregnant women with pre-eclampsia (100 cases), which is defined as "occurrence of hypertension after 20 weeks of gestation and proteinuria (presence of $300 \mathrm{mg}$ or more of protein in $24 \mathrm{~h}$ urine sample or $\geq 2+$ on dipstick)", was observed. Healthy pregnant women (100) were taken as controls. Women with thyroid disease, hypertension, renal disease, diabetes mellitus and liver diseases were excluded from the study groups. The medical records of both pre-eclamptic cases and normal pregnancies were reviewed for obstetrics history (age, parity and gestational age). Data were collected included glycosylated haemoglobin level (HbA1c \%), white blood cell (WBC) count, haematocrit $\%$ and platelets count (PC) to mean platelets volume (MPV) ratio. Additionally, liver and kidney function tests in normal and pre-eclamptic cases were recorded.

\subsection{Statistical Analysis}

Data were statistically analysed and expressed as mean \pm standard error (SEM) using a two-way analysis of variance ANOVA followed by paired t-test for multiple comparisons by using software Prism Version 7.

\section{RESULTS}

Figure 1 showing that the prevalence of preeclampsia is more prone in women (older than 35 years), which was almost $45 \%$ greater than in younger women (20-25 years old). Figure 2 shows that there was no significant difference in parity between the two study groups.

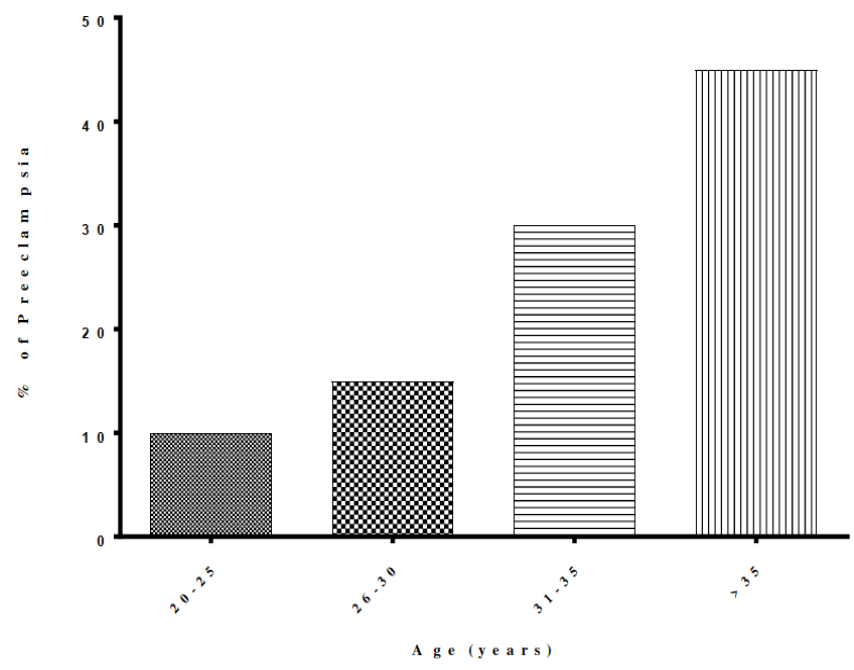

Figure 1: The percentage of preeclampsia occurrence at different ages.

There was no significant difference in WBC and haematocrit (HCT\%) between the two groups but it was found that PC to MPV ratio value was significantly lower in the cases compared with the controls, and the $\mathrm{HbA1c} \%$ value was significantly higher in the 


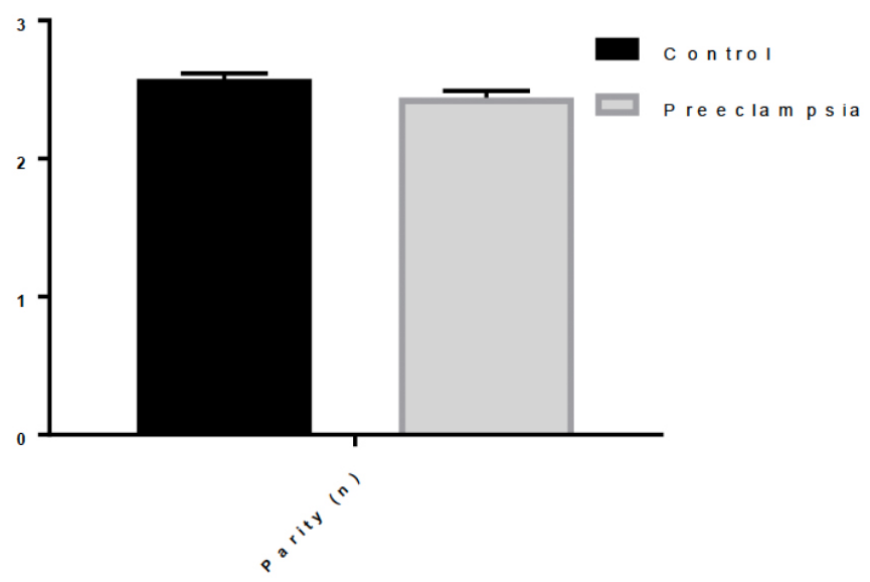

Figure 2: Parity in both preeclamptic pregnant cases and controls.

preeclamptic cases than the controls (Table 1, Figure 3).

Table 1: Median (Interquartile Range) of Haematological Values in Preeclamptic and Control Women

\begin{tabular}{|c|c|c|}
\hline Variable & Cases & Controls \\
\hline \hline $\mathrm{HbA} 1 \mathrm{c} \%$ & $6.86 \pm 0.195$ & $4.77 \pm 0.24^{*}$ \\
\hline $\mathrm{WBCs} \times 10^{3} / \mu \mathrm{L}$ & $8.11 \pm 0.064$ & $7.85 \pm 0.05$ \\
\hline Hematocrit $\%$ & $34.31 \pm 0.306$ & $33.4 \pm 0.547$ \\
\hline $\mathrm{PC} / \mathrm{MPV}$ & $21.16 \pm 0.475$ & $27.13 \pm 0.574^{*}$ \\
\hline
\end{tabular}

Table 2 and Figure 4 shows the significant increase in serum activities of liver enzymes, AST and ALT in preeclamptic cases mounted to $105.8 \%$ and $268.4 \%$, respectively, compared to the control group.



Figure 3: Median (interquartile range) of haematological values in preeclamptic and control women.

The renal indices, serum creatinine, urea and albumin were significantly higher in the preeclamptic women than the normal pregnant ones (Table $\mathbf{3}$ Figure 5).

Table 2: Average Values of Liver Function Tests, AST and ALT, in Normotensives and Pre-Eclamptic

\begin{tabular}{|c|c|c|}
\hline Variable & Cases & Controls \\
\hline \hline AST (U/L) & $38.5 \pm 4.039$ & $18.7 \pm 1.85^{*}$ \\
\hline ALT (U/L) & $47.9 \pm 3.954$ & $13.0 \pm 1.783^{*}$ \\
\hline
\end{tabular}

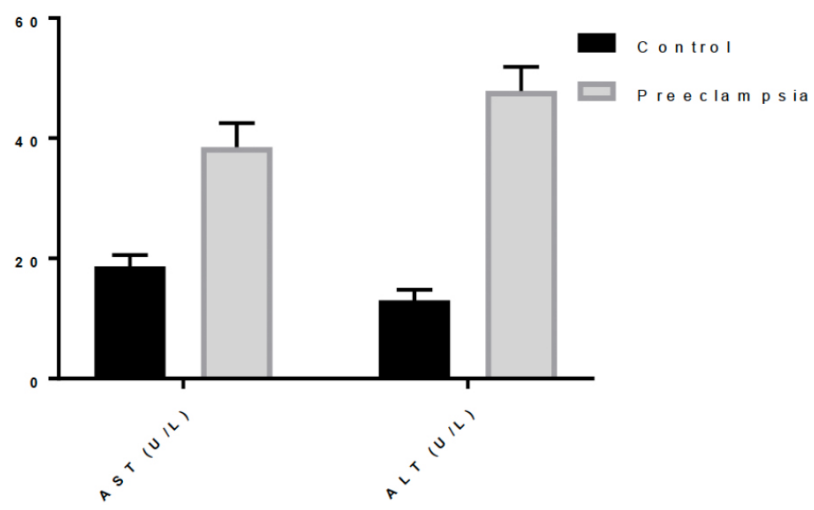

Figure 4: Average values of liver function tests, AST and $\mathrm{ALT}$, in normotensives and pre-eclamptic.

Table 3: Average Values of Serum Creatinine, Urea and Albumin in Normotensives and Pre-Eclamptic

\begin{tabular}{|c|c|c|}
\hline Variable & Cases & Controls \\
\hline \hline Urea $(\mathrm{mg} / \mathrm{dL})$ & $28.7 \pm 1.075$ & $20.49 \pm 0.884^{*}$ \\
\hline Creatinine $(\mathrm{mg} / \mathrm{dL})$ & $0.717 \pm 0.025$ & $0.537 \pm 0.017^{*}$ \\
\hline Albumin $(\mathrm{g} / \mathrm{dL})$ & $2.81 \pm 0.082$ & $3.34 \pm 0.098^{*}$ \\
\hline
\end{tabular}

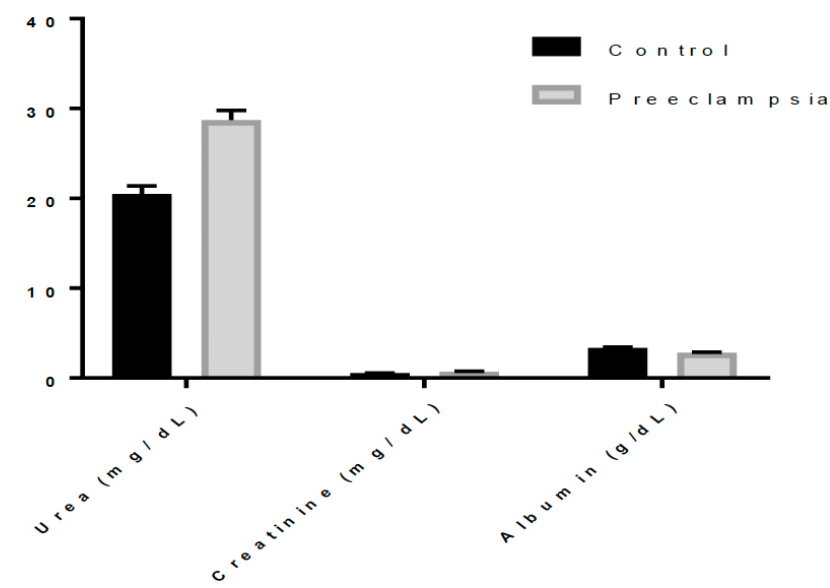

Figure 5: Average values of serum creatinine, urea and albumin in normotensives and pre-eclamptic.

\section{DISCUSSION}

The renal function indicators, serum creatinine, urea and egg whites were essentially higher in the pre- 
eclamptic women than the typical pregnant ladies that can be clarified as renal limit encounters physiological alterations in pregnancy. Sound pregnant ladies showed broad glomerular hyperfiltration by 40 to $60 \%$ in the second $50 \%$ of pregnancies [21]. This hyperfiltration appears to result essentially from a decline in the oncotic pressure [22].

Besides, an increased rate of renal plasma flow (ERPF) is found during pregnancy, ( $80 \%$ by 12 weeks' development) [22]. On the other hand, during preeclampsia these utilitarian changes in renal haemodynamic are one of a kind. The GFR in ladies with preeclampsia is basically lower when differentiated and sound gravid control subjects $(91 \mathrm{~mL} / \mathrm{min} / 1.73 \mathrm{~m} 2$ versus $149 \mathrm{~mL} / \mathrm{min} / 1.73 \mathrm{~m} 2$ ).

This lessening in the GFR during preeclampsia agrees with conventional histopathological changes in the kidney, called glomerular endotheliosis, which is depicted by fibrin proclamation, endothelial extending, and loss of hairlike space [23].

Disregarding the way that these renal histological changes have been considered pathognomonic for preeclampsia, this may not be the circumstance. A couple of social affairs have performed antenatal renal biopsies in the run of the mill pregnant ladies and ladies with gestational hypertension. For instance, Strevens et al. shown that five of twelve ordinary pregnant women had, however, astoundingly smooth verification of glomerular endotheliosis [24].

Pre-eclampsia is the most widely recognized glomerular ailment worldwide and stays a main source of newborn children and maternal mortality. Regardless of the way that the particular pathogenesis of this state of hypertension and proteinuria is so far divided, a solid line of evidence has recognized a lopsidedness of proangiogenic and against angiogenic proteins as a key factor in the headway of pre-eclampsia $[25,26]$. In addition, more thought has been starting lately directed to the renin-angiotensin-aldosterone system (RAAS), to give an understanding of the hypertension of preeclampsia [27]. The turmoil of the RAAS and the unevenness among angiogenic and threatening to angiogenic factors, which may be both fundamental to preeclampsia and incessant kidney sickness (CKD), may explain why a past loaded up with preeclampsia slants ladies to make CKD.

In the pathogenesis of pre-eclampsia, the placenta is the central organ since the departure of the placenta invalidates the contamination [28]. Fanatical appraisal reveals a couple of varieties from the ordinary including infarcts, arthrosis, apoplexy and interminable aggravation [29]. During conventional placentation, the undeveloped organism inferred cytotrophoblast cells assault the maternal winding veins. As a significant part of this methodology, the cytotrophoblasts get an endothelial phenotype [30]. In pre-eclampsia, the attack of the cytotrophoblasts into the winding veins is deficient; they are just present in the shallow layers of the decidua. The strange placentation is thought to prompt an arrival of emitted factors that enter the mother's dissemination, coming full circle in the clinical signs and manifestations of pre-eclampsia. The arrangement of hypofiltration during preeclampsia isn't clarified; both (renal) haemodynamic parts and auxiliary changes to essential renal changes are proposed [31]. Recently, podocyte modifications and podocyturia have been recorded during preeclampsia [31]. Proteinuria in patients with preeclampsia may not only be mediated by endothelial changes as portrayed traditionally rather it can also occur by aggravations of podocyte science including weakened perseverance, improved apoptosis and down-rule of nephron and other key proteins of cut stomach [32]. This investigation additionally demonstrats the huge increment in serum exercises of liver proteins, AST and ALT in preeclamptic cases mounted to $105.8 \%$ and $268.4 \%$, respectively, as compared to the control bunch that can be clarified as preeclampsia-induced liver illness is a turmoil remarkable to pregnancy and is every now and again found in the third trimester of pregnancy. Serious preeclampsia is characterized by outrageous height in foundational circulatory strain and proof of organ bargain. HELLP condition is a particular liver-related issue of pregnancy that was first portrayed by Weinstein in 1982 as a group of stars of clinical and lab variations from the norm in pregnant ladies in their third trimester [33].

Almost $70 \%$ of cases occur between weeks 27 and 37 , with $20 \%$ happening inside 48 hours of conveyance. Highlights of preeclampsia happen in most of patients giving HELLP disorder. $10 \%$ to $20 \%$ of patients with extreme preeclampsia will create HELLP. Liver contribution in preeclampsia isn't normal, in any case, but if present it means extreme malady. A few quality variations, for example, glucocorticoid receptor quality (GCCR), toll-like receptor 4 quality (TLR4), vascular endothelial development factor quality, FAS quality, bunch of separation 95 (CD95), and the coagulation factor $V$ Leiden change are related with expanded danger of HELLP in contrast to solid ladies. Insufficient vascular placental attack has been the main 
speculation in the aetiology of preeclampsia-eclampsia and HELLP disorder. Thrombotic microangiopathy prompts microangiopathic haemolytic frailty and liver harm in patients with HELLP. HELLP disorder has likewise been accounted for in a couple of cases that are related to abandons in $\beta$-oxidation of unsaturated fats [34].

\section{CONCLUSION}

Preeclampsia is a multisystem vascular turmoil of pregnancy that remains a main source of maternal and fetal horribleness and mortality. Preeclampsia stays an underrecognized chance factor for future cardiovascular and kidney illness in ladies and speaks to the conjunction of previous vascular hazard factors with endothelial injury of placental blood vessels. Preeclampsia stays a significant issue worldwide for mothers and children. Not withstanding concentrated examination, we have not had the option to improve the administration or early acknowledgment of preeclampsia. In any event, some portion of this is a result of the inability to normalize the way to deal with this unpredictable condition.

This investigation presumed that pregnant ladies with preeclampsia are progressively inclined to renal weakness, proteinuria, greasy liver, apoplexy, and raised liver compounds than ordinary pregnant ladies.

\section{CONFLICTS OF INTEREST}

There is no Conflicts of Interest regarding this work.

\section{ETHICS APPROVAL}

All the procedures were approved by the local committee of bioethics in Aljouf University in compliance with ethical standards. Data collected will be kept hidden and locked where others have no access to it.

\section{REFERENCES}

[1] Tranquilli AL, Dekker G, Magee L, et al. The classification, diagnosis and management of the hypertensive disorders of pregnancy: A revised statement from the ISSHP. Pregnancy Hypertens 2014; 4(2): 97-104. https://doi.org/10.1016/j.preghy.2014.02.001

[2] Mol BW, Roberts CT, Thangaratinam S, et al. Pre-eclampsia. Lancet 2016; 387(10022): 999-1011. https://doi.org/10.1016/S0140-6736(15)00070-7

[3] Douglas KA, Redman CW. Eclampsia in the United Kingdom. BMJ 1994; 309(6966): 1395-400. https://doi.org/10.1136/bmj.309.6966.1395

[4] Shennan AH, Redman C, Cooper C, et al. Are most maternal deaths from pre-eclampsia avoidable? Lancet 2012; 379(9827): 1686-1687. https://doi.org/10.1016/S0140-6736(11)60785-X
[5] Lain KY, Roberts JM. Contemporary concepts of the pathogenesis and management of preeclampsia. JAMA 2002; 287: 3183.

https://doi.org/10.1001/jama.287.24.3183

[6] Btett CY, Richard JL and Ananth SK. Pathogenesis of Preeclampsia, Annual review of Pathology: Mechanism of Disease 2010; Vol.5: 173-192.

https://doi.org/10.1146/annurev-pathol-121808-102149

[7] McMaster-Fay RA. "Pre-eclampsia: a disease of oxidative stress resulting from the catabolism of DNA (primarily fetal) to uric acid by xanthine oxidase in the maternal liver; a hypothesis". Bioscience Hypotheses 2008; 1: 35-43. https://doi.org/10.1016/j.bihy.2008.01.002

[8] Laresgoiti-Servitje E, Gómez-López N and Olson DM. "An immunological insight into the origins of pre-eclampsia". Hum Reprod Update 2010; 16 (5): 510-524. https://doi.org/10.1093/humupd/dmq007

[9] Excellence. NIfHaC. CG107 NICE Guideline: Hypertension in Pregnancy.2012.

[10] Bartsch E, Medcalf KE, Park AL, et al. High Risk of Preeclampsia Identification, Group "Clinical risk factors for preeclampsia determined in early pregnancy: systematic review and meta-analysis of large cohort studies". BMJ 2016; 353: i1753.

https://doi.org/10.1136/bmj.i1753

[11] Van den Boogaard E, Vissenberg R, Land JA, et al. "Significance of (sub)clinical thyroid dysfunction and thyroid autoimmunity before conception and in early pregnancy: a systematic review". Human Reproduction Update (Review). 2011; 17 (5): 605-619. https://doi.org/10.1093/humupd/dmr024

[12] Mol BW, Roberts CT, Thangaratinam S, et al. Pre-eclampsia. Lancet. 2016; 387(10022): 999-1011.

https://doi.org/10.1016/S0140-6736(15)00070-7

[13] Al-Jameil N, Aziz Khan F, Fareed Khan M, et al. "A brief overview of preeclampsia". Journal of clinical medicine research 2014; 6 (1): 1-7.

[14] Arulkumaran $\mathrm{N}$ and Lightstone L. "Severe pre-eclampsia and hypertensive crises". Best Practice \& Research Clinical Obstetrics \& Gynaecology 2013; 27 (6): 877-884. https://doi.org/10.1016/j.bpobgyn.2013.07.003

[15] Sibai, BM. Hypertension. In S. G. Gabbe, J. R. Niebyl, J. L. Simpson, M. B. Landon, H. L. Galan, E. R. M. Jauniaux, \& D. A. Driscoll (Eds.), Obstetrics: Normal and problem pregnancies 2012; Philadelphia, PA: W. B. Saunders.

[16] Haram K, Svendsen E, and Abildgaard U. The HELLP syndrome: Clinical issues and management. A review. BMC Pregnancy \& Childbirth 2009; 9: 8.

https://doi.org/10.1186/1471-2393-9-8

[17] Leeman L, Dresang LT, and Fontaine P. Hypertensive disorders of pregnancy. American Family Physician 2016; 93(2), 121-127.

[18] Igberase $G$ and Ebeigbe $P$. Eclampsia: ten-years of experience in a rural tertiary hospital in the Niger delta, Nigeria. Journal of Obstetrics and Gynaecology 2006; 26(5): 414-417. https://doi.org/10.1080/01443610600720113

[19] Adamu YM, Salihu HM, Sathiakumar N, et al. Maternal mortality in Northern Nigeria: a population-based study. European Journal of Obstetrics Gynecology and Reproductive Biology 2003; 109(2): 153-159. https://doi.org/10.1016/S0301-2115(03)00009-5

[20] Duley L. Pre-eclampsia and the hypertensive disorders of pregnancy. British Medical Bulletin 2003; 67: 161-176. https://doi.org/10.1093/bmb/ldg005

[21] Powe CE, Levine RJ, Karumanchi SA. Preeclampsia, a disease of the maternal endothelium: the role of antiangiogenic factors and implication. Journal of MaternalFetal and Neonatal Medicine 2009; vol. 22, no. 3, pp. 183190. 
[22] Salafia CM, Pezzullo JC, López-Zeno JA, et al. Placental pathologic features of preterm preeclampsia. Am J Obstet Gynecol 1995; 173: 1097-1105. https://doi.org/10.1016/0002-9378(95)91333-5

[23] Zhou $\mathrm{Y}$, Damsky $\mathrm{CH}$, Chiu $\mathrm{K}$, et al. Preeclampsia is associated with abnormal expression of adhesion molecules by invasive cytotropho- blasts. J Clin Invest 1993; 91: 950960.

https://doi.org/10.1172/JCl116316

[24] Hennessy A and Makris A. Preeclamptic nephropathy. Nephrology 2011; 16: 134-143. https://doi.org/10.1111/j.1440-1797.2010.01411.x

[25] Kayode O, Osungbade and Olusimbo K. Ige. Public Health Perspectives of Preeclampsia in Developing Countries: Implication for Health System Strengthening 2011; 2011, 6-9. https://doi.org/10.1155/2011/481095

[26] Sibai BM. Diagnosis and management of gestational hypertension and preeclampsia. Obstet Gynecol. 2003; 102(1): 181-192.

https://doi.org/10.1097/00006250-200307000-00033

[27] Duley L. Maternal mortality associated with hypertensive disorders of pregnancy in Africa, Asia, Latin America and the Caribbean. Br J Obstet Gynaecol 1992; 99: 547-553. https://doi.org/10.1111/j.1471-0528.1992.tb13818.x

[28] Maynard SE, Min JY, Merchan J, et al. Excess placental soluble fms-like tyrosine kinase 1 (sFlt1) may contribute to endothelial dysfunction, hypertension, and proteinuria in preeclampsia. J Clin Invest 2003; 111: 649-658. https://doi.org/10.1172/JCl17189
[29] Venkatesha S, Toporsian M, Lam C, et al. Soluble endoglin contrib- utes to the pathogenesis of preeclampsia. Nat Med 2006; 12: 642-649.

https://doi.org/10.1038/nm1429

[30] Cornelis T, Odutayo A, Keunen J, et al. The kidney in normal preg- nancy and preeclampsia. Semin Nephrol 2011; 31: 414.

https://doi.org/10.1016/j.semnephrol.2010.10.002

[31] Garovic VD, Wagner SJ, Turner ST, et al. Urinary podocyte excretion as a marker for preeclampsia. Am J Obstet Gynecol 2007; 196: 320.e1-320.e7. https://doi.org/10.1016/j.ajog.2007.02.007

[32] Henao DE, Mathieson PW, Saleem MA, et al. A novel renal perspec- tive of preeclampsia: a look from the podocyte. Nephrol Dial Trans- plant 2007; 22: 1477. https://doi.org/10.1093/ndt/gfl804

[33] Weinstein L. Syndrome of hemolysis, elevated liver enzymes, and low platelet count: a severe consequence of hypertension in pregnancy. Am J Obstet Gynecol 1982; 142: 159-167. https://doi.org/10.1016/S0002-9378(16)32330-4

[34] Bearelly D, Hammoud GM, Koontz G, et al. Preeclampsiainduced liver disease and HELLP syndrome. In: Ibdah, J. A., ed. Maternal Liver Disease. 1st ed. Austin, TX: Landes Bioscience 2012; 73-92.

Received on 31-07-2020

Accepted on 02-09-2020

Published on 15-10-2020

DOI: https://doi.org/10.29169/1927-5951.2020.10.05.16

(c) 2020 Hendawy et al.; Licensee SET Publisher.

This is an open access article licensed under the terms of the Creative Commons Attribution Non-Commercial License (http://creativecommons.org/licenses/by-nc/3.0/) which permits unrestricted, non-commercial use, distribution and reproduction in any medium, provided the work is properly cited. 